\title{
New Paradigms in Stock Market Indexing
}

by

\author{
Derek Jun, Merrill Lynch \\ Burton G. Malkiel, Princeton University \\ CEPS Working Paper No. 166
}

January 2008

Acknowledgements: The authors would like to express their gratitude to the anonymous referee and all those that have helped improve the quality of the paper. This research was supported in part by the Center for Economic Policy Studies at Princeton University.

*The opinions expressed in this publication are entirely those of the authors and, in expressing their opinions, the authors are not acting as employees or agents of Merrill Lynch nor do the opinions expressed herein necessarily reflect those of Merrill Lynch. Merrill Lynch does not accept any liability for any content contained in the publication, or any errors or omissions. The information contained in this publication should not be considered as a recommendation, an offer or a solicitation of an offer to buy and sell securities or other instruments from/to Merrill Lynch. Merrill Lynch shall not be responsible for any third-party claims, actions, or demands made relating to the publication. 


\begin{abstract}
Considerable recent interest has been shown in a new set of stock-market indices that are weighted by fundamental factors such as sales, earnings, dividends or book values, rather than by capitalization. In this paper, we analyze the performance of Fundamental Indexing TM ("FI"). First, we show that the source of FI's recent excellent performance is not from its ability to systematically arbitrage mispricing in a noisy market but from increasing the portfolio's exposure to stocks with low price-to-book values and with small capitalizations. We find that FI does not produce a positive alpha when its excess returns are explained by the Fama-French three-factor model of CAPM beta, the value premium and the size premium. Second, we show that it is possible to construct a portfolio of exchange-traded funds with similar factor loadings that can replicate, and sometimes, even outperform FI. However, we caution investors not to expect consistent outperformance from portfolios tilted towards value and small-cap stocks. Historical data shows evidence of mean reversion in the performance of such strategies.
\end{abstract}


Considerable recent interest has been shown in a new set of indices that are weighted by certain fundamental factors such as sales, earnings, dividends or book values, rather than by capitalization. Capitalization-weighted indexing, until now the dominant approach to index construction, has come under fire for overweighting (temporarily) overvalued stocks and underweighting undervalued ones in a portfolio. The best known of these new "fundamentally weighted" indices that claim to improve upon such deficiencies of a capweighted index is the Research Affiliates Fundamental Index ${ }^{\mathrm{TM}}$ (“RAFI", FTSE RAFI US 1000 - Ticker PRF). The new RAFI index contains 1000 stocks weighted by fundamental measures of book value, earnings, etc., and has outperformed traditional large-cap indices such as the Standard and Poor's 500 index and the Russell 1000 by margins of over 300 basis points per year during the 2000s. Such performance has emboldened the proponents of the fundamental index to claim that this new method of indexing could replace the 'old paradigm' of capitalization weighted indexing. Fundamental Indexing TM ("FI") is one of the most successful new investment products to be launched during the 2000s. In a little over two years it has attracted over $\$ 10$ billion in portfolio investments. The product has been successful both in its appeal to institutional investors and in its ability to gather assets from retail investors in the burgeoning ETF market place. FI has been a marketing sensation. Moreover the actual performance of the FI portfolio has been excellent. During 2005, 2006, and first half of 2007, when the portfolio has been "live" rather than simply backtested, FI has outperformed both the S\&P 500 and the Russell 1000 capitalization weighted indices by substantial margins. Since inception FI has had an annualized net return of $13.1 \%$, 
outperforming the exchanged traded funds tracking the S\&P500 (Ticker: SPY) and the Russell 1000 (Ticker: IWB) by 200 and 155 basis points, respectively.

Fundamental Indexation has also been effective in back-tested results both in Europe and Asia. Return statistics from 1987 through 2005 suggest that fundamentallyweighted indexes have outperformed capitalization-weighted indexes in Greece, Ireland, France, Switzerland, Germany and Denmark by over 200 basis points per annum. In Japan the out performance has been greater than 300 basis points a year. In emerging markets, the technique has shown even greater excess returns over capitalizationweighted indexes. Moreover, these higher returns have been achieved with lower volatility, thus producing higher Sharpe ratios ${ }^{1}$.

In this paper we take a critical look at Fundamental Indexing ${ }^{\mathrm{TM}}$ and come to several conclusions. First we believe FI should be considered active management rather than indexing. Moreover, the reason for its success in outperforming certain market benchmarks is, in our judgment, that it relies on two factor tilts that researchers have understood for years. It is possible to replicate FI returns with a variety of ETFs that employ similar factor tilts. FI does not produce an "alpha" when measured against a Fama-French (1993) three-factor risk model. Finally, it is far from certain that the factor tilts implicit in FI will continue to be as productive as they have been during recent history when the stock market has adjusted from an extraordinary bubble in the pricing of high technology growth stocks.

\footnotetext{
${ }^{1}$ Back-tested results have been made available to us by Research Affiliates, LLC, and Nomura Securities.
} 


\section{The Putative Rationale for Fundamental Indexing ${ }^{\mathrm{TM}}$}

The putative rationale for FI has been stated by Arnott, Hsu, and Moore (2005) as well as by Treynor (2005) and Siegel (2006). The argument for weighting by other than capitalization seems extraordinarily appealing. An index-based on price will necessarily overweight "overvalued" stocks and underweight the "undervalued" ones. If two stocks should be selling at their "intrinsic values" of $\$ 100$ each, but one sells at $\$ 130$ and the other for $\$ 90$, then an index weighted by price (capitalization) will tend to give too much weight to the "overvalued" stock. The simple factor of "noise" may make prices stray temporarily from their intrinsic values, and price weighting will lead to the portfolio holding too much of the temporarily "overvalued" stocks. FI tries to avoid the problem by weighting each stock not by capitalization but rather by its "economic footprint." Economic footprint is determined by factors such as revenues, book values, earnings, etc. Thus, weightings are determined by measures of a company's relative size in the economy, not by share of market capitalization. In a situation where "irrational exuberance" has pushed high tech stocks to enormous price-earnings multiples and to too large a share of the total market capitalization, FI will underweight the tech sector relative to its cap-weighted share of the index and thereby protect the investor from suboptimal performance.

But we can imagine another scenario whereby FI could actually discriminate against "undervalued" stocks. Suppose we have two stocks A and B selling at \$100 per share with identical earnings and revenues. But suppose further that these two stocks do not have the same intrinsic values. Assume that A has far greater investment opportunities and therefore much better growth prospects than B. For that reason A 
deserves to sell at a higher price than B. In this case, if both stocks are equally weighted, FI will hold too much of stock B which is the overvalued stock. In order for FI to produce superior outcomes, the fundamental factors such as earnings must be assumed to be a better measure of "true value" than prospective "growth prospects." When Google was selling at \$100 a share with very low current earnings, revenues, and book value, etc., it may have been "undervalued" rather than "overpriced" and FI will systematically hold less of it than it should. Only if "growth" stocks tend to be regularly overpriced will FI give us a foolproof method of avoiding overpriced securities.

\section{The Factor Tilts Inherent in FI}

To the extent that earnings and book values are some of the factors used to weight stocks in the portfolio, FI will systematically overweight "value" stocks and underweight "growth" stocks. Moreover, to the extent that FI attempts to underweight stocks with (temporarily) high market capitalizations, there will be a tendency for an FI portfolio to contain smaller-capitalization stocks compared with a cap-weighted index. According to Eugene Fama and Kenneth French (2007), RAFI is a "triumph of marketing, and not of new ideas." It's simply a "repackaging" of ideas that have been in the academic literature for years. This point has also been forcefully presented by Asness (2007) and Perold (2007).

A long literature in empirical finance has isolated a "value" effect in asset pricing. Studies such as DeBondt and Thaler (1987) and Keim (1988) have shown that stocks selling at low prices relative to their book values $(\mathrm{P} / \mathrm{BV})$ have generated higher returns for investors. Similar results have been shown for stocks selling at low price-earnings 
multiples and at low multiples to their sales. One can interpret such findings as being inconsistent with efficient markets. Portfolios made up of stocks with low P/BV ratios earn excess risk-adjusted returns when risk is measured by beta from the Capital Asset Pricing Model (CAPM). But any test of market efficiency is a joint test of the relationship of return to P/BV and the efficacy of CAPM's beta to fully measure risk. According to Fama and French (1992), the ratio of price to book value itself is a risk measure and therefore the larger returns generated by low P/BV stocks are simply compensation for risk.

Investigators such as Basu (1983) have also found a strong relationship between company size (measured by total market capitalization) and returns. Smaller firms appear to generate higher returns than large firms. Again, the interpretation of these results is controversial. The excess returns of small firms can be interpreted as an inefficiency. The interpretation of Fama and French, however, is that both $\mathrm{P} / \mathrm{BV}$ and size are risk factors in addition to beta. Low $\mathrm{P} / \mathrm{BV}$ stocks are often those in some financial distress and smaller stocks may be far more sensitive to economic shocks than are larger firms.

\section{Empirical Evidence on FIs Factor Tilts}

One direct method of measuring the factor tilts inherent in FI portfolios is to perform a regression analysis of the monthly FI returns in the United States against the Fama-French (1993) three-factor model. Fama and French argue that the Capital Asset Pricing Model (CAPM) should be augmented by two additional risk factors, which are 
company size and market to book ratio. Thus, risk is captured by CAPM's beta, M/B, and Equity Capitalization (size) measures. In equation form

$$
\text { Feturn =f (CAPTIF, High } \frac{M}{B}-\text { Low } \frac{M}{B}, \text { S-B) }
$$

The first risk factor is the traditional CAPM beta. The second factor is the difference in returns between high market-to-book companies and firms with low ratios of market value to book value. The third variable measures the difference in returns of small firms (S) minus big firms (B). The data series used were compiled by Fama and French. The Fama-French three factor model has been successfully applied not only in the United States but in Europe as well. The ability of the model to explain the cross-section of European stock returns has been documented by Petrella (2005) and Heston, Rouwenhorst, and Wessels (2008).

We have regressed the FI returns against the three Fama-French (FF) risk factors for many different periods. Sample results for different periods from January 1979 through March 2007, which include backtested as well as "live" results, are shown in Exhibit 1 below.

Note that the three F-F risk factors can "explain" the FI returns with very high $\mathrm{R}^{2} \mathrm{~s}$. Note also that the $\mathrm{t}$-values on all three risk factors are highly significant. Finally we see that the $\alpha$ 's of the regression, the measure of excess returns above those explained by risk, are exactly zero. We conclude that the FI returns can fully be explained by their factor weighting and there is no evidence that FI isolates undervalued securities. A zero "alpha" or excess return is generated by the FI method of weighting the portfolio.

\section{[EXHIBIT 1 GOES HERE]}


An additional method to show that the FI results depend on factor tilts is to replicate the FI returns with a portfolio of indices that contain the similar factor loadings. We have experimented with several such portfolios. While only one of these is presented, we find that there are a variety of ways to produce similar (or even larger) returns than FI. We agree with Arnott et. al., that FI is not simply a value portfolio. It has characteristics of both greater value and smaller size than a capitalization weighted portfolio.

If we are correct that FI is simply making a bet on the size and value effect, there exist a number of other options readily available to any investor to gain the same risk/return exposure. Three indices come to the forefront in capturing the size and value risk factors. First is the S\&P Equal Weighted Index (S\&P EWI), which has the same 500 large stocks as the S\&P 500 but with equal weighting of $0.2 \%$ for each underlying stocks. Such a weighting scheme in the S\&P EWI will overweigh smaller stocks and value stocks relative to the S\&P 500. Another candidate is the S\&P Midcap Value index which is constructed from the stocks with value characteristics in the next 400 large stocks after the 500 in the S\&P 500. Another candidate is the Russell 1000 Value Index, which contains those stocks in the R1000 with value characteristics. By analyzing the performance of RAFI and these three indices that emphasize the same risk factors driving the performance of the fundamental index, we can further illuminate the reasons for the FI results.

Exhibit 2 shows the returns of a portfolio made up of one-third shares of the aforementioned three indices. The portfolio is constructed as 1/3 the S\&P 500 equalweighted portfolio, 1/3 the S\&P mid-cap value portfolio, and 1/3 the Russell 1000 Value 
portfolio. Note that while the FI portfolio (gross of fees) outperformed the S\&P 500 index by a substantial amount during the $2000-2007$ period, a portfolio comprised of the three indices above outperformed FI and, on a risk adjusted basis, had a higher Sharpe ratio. The portfolio shown in Exhbit 2 does not contain an identical list of stocks as the FI portfolio, which is based on the underlying 1000 stocks in the Russell index. Thus our portfolio is not a perfect apples to apples comparison. But our portfolio does show that we can generate similar returns to FI with a combination of indices that contain the same factor tilt as FI.

\section{[EXHIBIT 2 GOES HERE]}

\section{The Controversy over the Size and Value Effects}

The size and value effects have been studied by financial economists for years. As indicated above, researchers who first discovered the effects considered them inefficiencies. One explanation is offered by behavioral finance economists. Investors overemphasize their own skill, especially when it comes to their ability to predict the future earnings growth of individual companies. Behavioral explanations ${ }^{2}$ appear particularly appealing in helping us understand the extraordinary bubble in large capitalization high-technology growth stocks during 1999 and early 2000 and the suboptimal behavior of the investors who held them.

Fama and French (1993), however, attribute the size and value effects to risk. They claim that smaller companies are inherently riskier than larger firms and that they are more susceptible to the variety of systematic economic risks that influence stock prices. Similarly, they argue that "value" stocks are also riskier. A low price-to book

\footnotetext{
${ }^{2}$ See Lakonishok, Shleifer, and Vishny (1994) and Shiller (2000).
} 
ratio is often, in their view, a sign of financial distress and greater susceptibility to economic shocks. Lakonishok, et. al. (1994) vigorously deny that value stocks are fundamentally riskier.

The controversy regarding the reasons the size and value effects have often produced high returns is important in judging the sustainability of the large returns generated by FI and similar strategies. Suppose the size and value effect are, in fact simply the reward for accepting higher risk. Larger returns for accepting higher risk should be sustainable in the long run. Risk deserves a reward even in the most highly efficient markets. But if the value and size effects are inefficiencies, resulting from the suboptimal behavior of investors, why should they persist? Even those who believe that markets are inefficient must admit that exploitable inefficiencies will eventually be arbitraged away. It is hard to believe that hundred dollar (or hundred Euro) bills will lie on the ground perpetually without someone eventually picking them up.

\section{Will Value (and size) Tilts Continue to be Productive?}

Indeed the long-run results from value-style investing suggest considerable mean reversion in investment styles rather than consistent excess returns. Exhibit 3 shows the relative results from different mutual funds investing with either a "growth" or "value" mandate. From the mid-1960's to the present, "value" mutual fund managers have usually outperformed "growth" managers (although not during the late $1990 \mathrm{~s}^{3}$ ). In earlier periods, from the late thirties to the mid-sixties, growth stocks appeared to be the persistent winners. There appears to be considerable mean reversion evident in the time

\footnotetext{
${ }^{3}$ Most of the empirical studies have used data from the mid or late 1960 s to isolate the size and value effects. See, for example, Fama and French (1992).
} 
series. Consequently factor tilts favoring value and size may be far less productive than they were during the first seven years of the 2000s.

\section{[EXHIBIT 3 GOES HERE]}

\section{The Compression of Price-Earnings Multiples}

The strong compression of price-earnings multiples, both in the United States and in European and Japanese markets, also would appear to limit the possibilities for Fundamental Indexing ${ }^{\mathrm{TM}}$ to produce returns that are higher than those of the broad market indexes. During the late 1990s and early 2000 price-earnings multiples in the U.S. market were unusually disperse. Just over one quarter of the stocks in the Standard \& Poor's 500 Stock Index were within 20 percent of the median P/E multiple of the market. As of 2006 and early 2007, however, well over half the stocks in the index were selling at P/E multiples within 20 percent of the market median. Exhibit 4 presents a time series of the percentage of S\&P 500 stocks selling within 20 percent of the median market multiple.

\section{[EXHIBIT 4 GOES HERE]}

This compression of price-earnings multiples is likely to make "value" tilts far less productive in the future than they were during the early 2000 s. Indeed, in the environment of compressed multiples it is more likely that a "growth" stock tilt will produce the most satisfactory returns. A compression of multiples is also evident in Europe and in all the developed international markets as well as in the United Sates. 


\section{Conclusion}

The central thesis of Fundamental Indexing is that weighting the components of an index by their "economic footprint" allows the portfolio to avoid some of the deficiencies of a capitalization weighted index, such as over-weighting of overvalued stocks and underweighting of undervalued stocks. In this paper, we argue that the recent outperformance of RAFI over that of traditional cap-weighted indices has not been a result of the strategy's ability to arbitrage the inefficiency of cap-weighted indexing, but a reward from loading on factor tilts - namely the size and value "risk" factors. The size and value factors has long been studied by academics and we have presented evidence that the performance of the FI can be explained by the three-factor Fama-French model. Given this view, we have offered alternative ways in which investors can access exposure to the risks factors, which we believe drives FI's performance.

We appreciate that many investors will be willing to bet on the long-run excess performance of value tilt strategies, through either the RAFI or through a combination of ETF's. But we have presented longer-term evidence that should caution investors from dramatically shifting the indexed core holdings of their portfolios away from capitalization weighting. As historical data clearly show, the dissected value and growth components of the market have for decades had a tug-of-war of outperforming each other. Over the past 30 years "value" stocks have enjoyed substantially superior performance. But in the current market environment, the tide could turn in favor of growth oriented companies (and larger capitalization stocks), especially given the compression of price-earnings multiples in the market. We are certainly not claiming that we can predict the future and that growth stocks will outperform value stocks over any 
future period. Our argument is simply that very low cost capitalization weighted index funds are unlikely to be knocked off their perch as the preferred index fund for the core of an equity portfolio. 


\section{References}

Arnott, Robert and Jason Hsu and Phillip Moore, "Fundamental Indexation," 2005, Financial Analysts Journal, March, April

Asness, Clifford, "Capitalization - vs. Fundamentally-Weighted Indices, Manuscript 2007

Banz, Frolf, 1981, “The Relationship Between Return and Market Value of Common Stocks, Journal of Financial Economics, March

Fama, Eugene and French, Kenneth, "The Cross-Section of Expected Stock Returns," 1992, Journal of Finance, pp 427-465.

, "Common Risk Factors in the Returns on Stocks and Bonds," 1993,

$\underline{\text { Journal of Financial Economics }}$

Heston, Steve L. and Rouwenhorst, K. Geert and Wessels, Robert E., "The Role of Beta and Size in the Cross-section of European Stock Returns," European Financial Management, 2008, Forthcoming

Ibbotson Associates, Stocks, Bonds, Bills, and Inflation: 2007 Yearbook

Lakonishok, Josef and Adrei Schleifer and Robert Vishny, 1995 "Contrarian Investment, Extrapolation, and Risk," Journal of Finance, pp $541-578$

Malkiel, Burton G., A Random Walk Down Wall Street, Norton 1973, 2007

Perold, Andre, 2007, "Fundamentally Flawed Indexing," Financial Analysts Journal, Nov.Dec.

Petrella, Giovanni, “Are Euro Area Small Cap Stocks an Asset Class? Evidence from Mean-Variance Spanning Tests,” European Financial Management, VOL 11:2 March 2005

Sheller, Robert, 2000, Irrational Exuberance, Princeton University Press

Treynor, Jack, 2005, "Why Market-Valuation-Indifferent Indexing Works," Financial Analysts Journal, September, October 


\section{Exhibit 1}

\section{FI Returns Vs Fama French Risk Factors}

Regression results from explaining the excess returns on the fundamental index against the Fama-French factors of Beta (excess returns on the S\&P 500), M/B Risk Factor (the value premium), and Size Risk Factor (the small-cap premium) are presented in three sample periods starting in (1) January 1962, (2) January 1979, and (3) January 1996 and ending in March 2007. The y-intercept of the regression is presented as $\alpha$ below.

\begin{tabular}{ccccccc} 
Period & $\mathrm{R}^{2}$ & $\begin{array}{c}\text { T-Value } \\
\text { Beta }\end{array}$ & $\begin{array}{c}\text { T-Value } \\
\text { M/B Risk } \\
\text { Factor }\end{array}$ & $\begin{array}{c}\text { T-Value } \\
\text { Size Risk } \\
\text { Factor }\end{array}$ & $\alpha$ & (t-value) \\
\hline \hline Jan 1962 - March 2007 & 0.97 & 128.9 & 29.3 & -6.91 & 0.00 & $(-0.39)$ \\
Jan 1979 - March 2007 & 0.96 & 90.8 & 21.5 & -7.18 & 0.00 & $(0.35)$ \\
July 1996 - March 2007 & 0.93 & 40.76 & 13.07 & -3.95 & 0.00 & $(0.07)$
\end{tabular}




\section{Exhibit 2}

\section{Comparative Performance: January 2000 through June 2007}

A comparison of return characteristics of the (1) Fundamental Index, (2) S\&P 500 Index and (3) a hypothetical portfolio for the sample period of January 2000 through June 2007. The fundamental index returns presented here are gross of fees. The hypothetical portfolio is comprised of 33\% S\&P EWI, 33\% Midcap Value, and 33\% Russell 1000 Value indices and is rebalanced monthly.

\begin{tabular}{lccc}
\multicolumn{1}{c}{ Period } & FI (gross) & S\&P 500 & Portfolio \\
\hline \hline Annualized Returns & $11.20 \%$ & $2.26 \%$ & $12.31 \%$ \\
Monthly Volatility & $3.86 \%$ & $4.03 \%$ & $4.11 \%$ \\
Sharpe Ratio & 1.94 & -0.35 & 2.10
\end{tabular}




\section{Exhibit 3}

\section{How Persistent is the Value Effect?}

Reversion to the Mean:

Growth Funds vs. Value Funds, 1937 - 3/2007

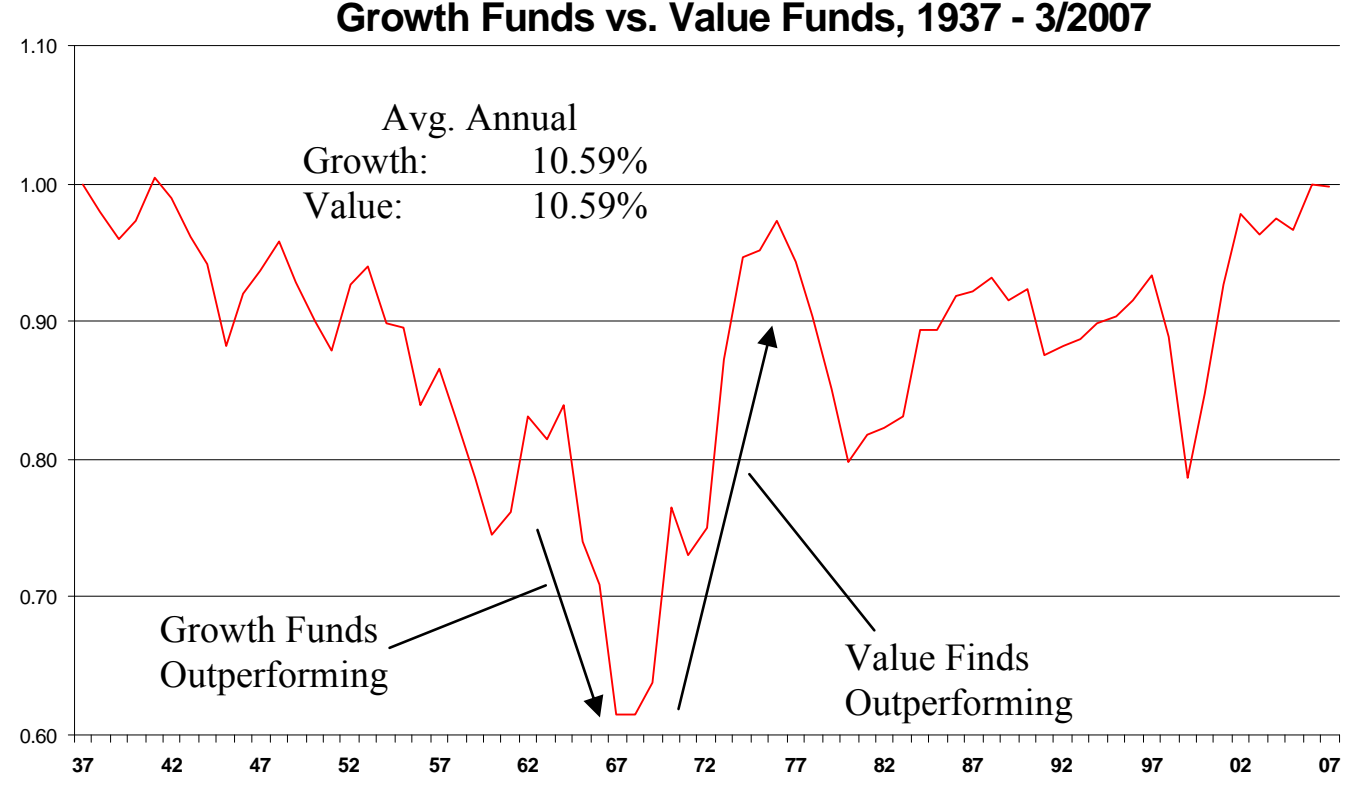

Growth = Lipper Growth

Value $=$ Lipper Growth \& Income 


\section{Exhibit 4}

Percentage of S\&P 500 Stocks Within $20 \%$ Of The Median P/E

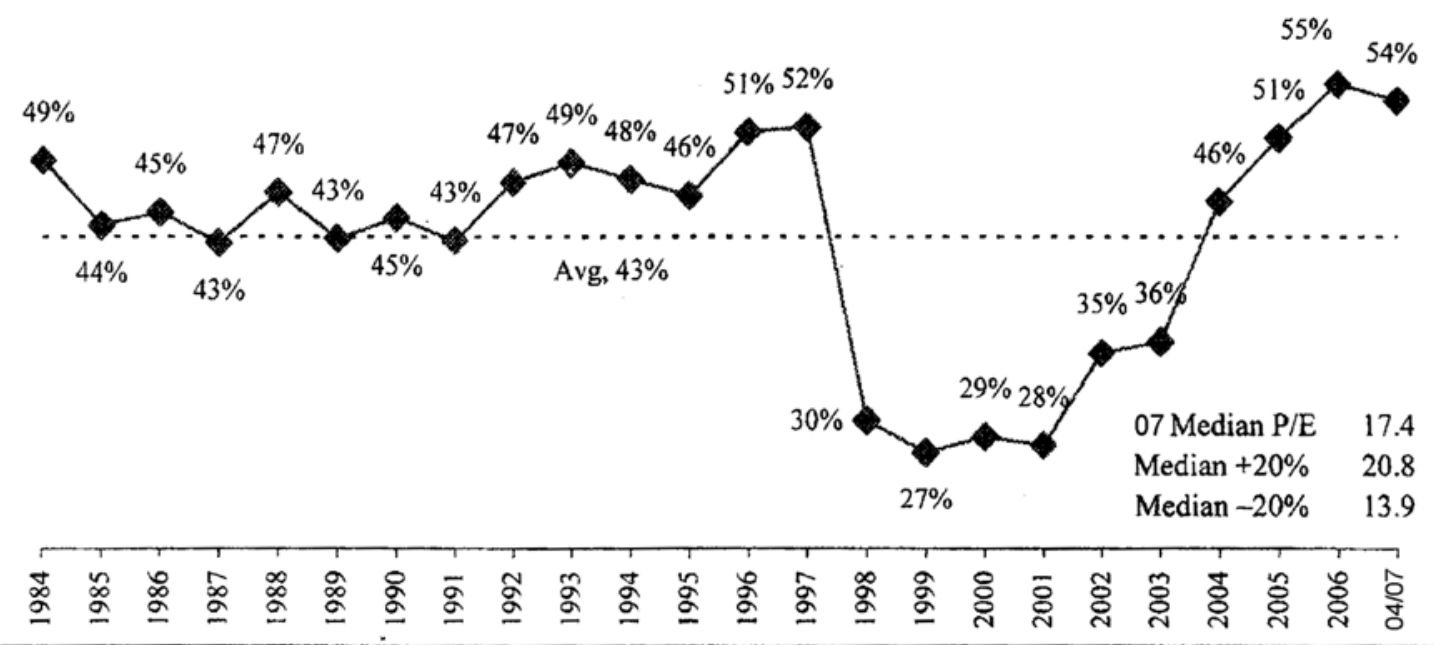

Source: FactSet, Morgan Stanley Research 